\title{
Gold nanorods induce early embryonic developmental delay and lethality in zebrafish (Danio rerio)
}

Bárbara Mesquita, Isabel Lopes, Susana Silva, Maria João Bessa, Maksim Starykevich, Jorge Carneiro, Tiago L. P. Galvão, Mário G. S. Ferreira, João Tedim, João Paulo Teixeira \& Sónia Fraga

To cite this article: Bárbara Mesquita, Isabel Lopes, Susana Silva, Maria João Bessa, Maksim Starykevich, Jorge Carneiro, Tiago L. P. Galvão, Mário G. S. Ferreira, João Tedim, João Paulo Teixeira \& Sónia Fraga (2017) Gold nanorods induce early embryonic developmental delay and lethality in zebrafish (Danio rerio), Journal of Toxicology and Environmental Health, Part A, 80:13-15, 672-687, DOI: 10.1080/15287394.2017.1331597

To link to this article: https://doi.org/10.1080/15287394.2017.1331597

Published online: 11 Jul 2017.

Џ Article views: 111

View Crossmark data ¿־
Submit your article to this journal $₫$ 


\title{
Gold nanorods induce early embryonic developmental delay and lethality in zebrafish (Danio rerio)
}

\author{
Bárbara Mesquitaa ${ }^{\mathrm{a}, \mathrm{b}}$, Isabel Lopes ${ }^{\mathrm{c}}$, Susana Silva ${ }^{\mathrm{a}, \mathrm{b}}$, Maria João Bessaa, ${ }^{\mathrm{a}, \mathrm{b}}$, Maksim Starykevich ${ }^{\mathrm{d}}$, Jorge Carneiro ${ }^{\mathrm{d}}$, \\ Tiago L. P. Galvãod, Mário G. S. Ferreira ${ }^{d}$, João Tedim ${ }^{d}$, João Paulo Teixeiraa ${ }^{\mathrm{a}, \mathrm{b}}$, and Sónia Fraga ${ }^{\mathrm{a}, \mathrm{b}}$ \\ aEPIUnit- Instituto de Saúde Pública, Universidade do Porto, Porto, Portugal; 'bepartamento de Saúde Ambiental, Instituto Nacional de \\ Saúde Doutor Ricardo Jorge, Porto, Portugal; ' $D$ Departamento de Biologia \& CESAM, Campus de Santiago, Aveiro, Portugal; ${ }^{\mathrm{d} D e p a r t a m e n t o}$ de \\ Engenharia de Materiais e Cerâmica, CICECO, Aveiro, Portugal
}

\begin{abstract}
Due to their unique electronic and optical features, gold nanoparticles (AuNP) have received a great deal of attention for application in different fields such as catalysis, electronics, and biomedicine. The large-volume manufacturing predicted for future decades and the inevitable release of these substances into the environment necessitated an assessment of potential adverse human and ecological risks due to exposure to AuNP. Accordingly, this study aimed to examine the acute and developmental toxicity attributed to a commercial suspension of Au nanorods stabilized with cetyltrimethylammonium bromide (CTAB-AuNR) using early embryonic stages of zebrafish (Danio rerio), a well-established model in ecotoxicology. Zebrafish embryos were exposed to CTAB-AuNR $(0-150 \mu \mathrm{g} / \mathrm{L})$ to determine for developmental assessment until $96 \mathrm{hr}$ post fertilization (hpf) and lethality. Uptake of CTAB-AuNR by embryos and nanoparticles potential to induce DNA damage was also measured at 48 and $96 \mathrm{hpf}$. Analysis of the concentration-response curves with cumulative mortality at $96 \mathrm{hpf}$ revealed a median lethal concentration $\left(\mathrm{LC}_{50,96 \mathrm{~h}}\right)$ of $110.2 \mu \mathrm{g} / \mathrm{L}$. At sublethal concentrations, CTAB-AuNR suspensions were found to produce developmental abnormalities such as tail deformities, pericardial edema, decreased body length, and delayed eye, head, and tail elongation development. Further, less than $1 \%$ of the initial concentration of CTAB-AuNR present in the exposure media was internalized by zebrafish embryos prior to (48 hpf) and after hatching (96 hpf). In addition, no marked DNA damage was detected in embryos after exposure to CTAB-AuNR. Overall, CTAB-AuNR suspensions produced lethal and sublethal effects on zebrafish embryos with possible repercussions in fitness of adult stages. However, these results foresee a low risk for fish since the observed effects occurred at concentrations above the levels expected to find in the aquatic environment.
\end{abstract}

\section{Introduction}

Owing to their unique physicochemical properties and great potential of application in different areas, gold nanoparticles (AuNP) are attracting scientific, industrial, and societal attention. Currently, AuNP are being investigated for enhancing the efficiency of photovoltaic devices (Yu et al., 2015), for environmental monitoring and remediation (Qian et al., 2013; Saha et al., 2012) and in the biomedical field, are being exploited as imaging agents, biosensors, and drug/gene delivery platforms (Alkilany et al., 2012; Baptista et al., 2011; Hornos Carneiro \& Barbosa, 2016; Kumar et al., 2013; Zhao \& Castranova, 2011; Zhou et al., 2015). According to the Project on Emerging Nanotechnologies (PEN) consumer products online inventory (http://www. nanotechproject.org/cpi/, last visited on February 2017), there are currently 25 products containing AuNP available in the market, most of these in the personal care and cosmetic category. One of the advantages of AuNP over other materials is related to ease in synthesis, control of size and shape, and in surface modification. Because anisotropic AuNP display significantly different optical properties, when compared with Au nanospheres, several methods for their synthesis such as lithography, electrochemical, photochemical, and seed-mediated growth were developed and optimized (Li et al., 2014). The seed- 
mediated growth is currently the most widely used to produce Au nanorods (AuNR) as this enables better dispersion and control over the size and shape. This method employs cetyltrimethylammonium bromide (CTAB), a cationic surfactant, which at high concentrations may exert toxic effects to biota (Grzelczak et al., 2008; Jana et al., 2001; Xia et al., 2015).

Due to the inert and biocompatible nature of $\mathrm{Au}$ in the bulk form, AuNP were initially regarded as nontoxic and less scrutinized in terms of their safety compared with other manufactured nanomaterials (MNM). However, increasing evidence shows that exposure to AuNP may be associated with adverse effects (Alaraby et al., 2016; Alkilany et al., 2009; Hornos Carneiro \& Barbosa, 2016; Kermanizadeh et al., 2016). Considering the socioeconomic impact that AuNP are expected to reach in the upcoming years and the inevitable release of these substances into the environment, it is important to determine the implications of exposure to these MNM, particularly the ones already available in the market, on both organisms and, ultimately, in ecosystems. Currently, data on environmental concentrations of MNM are scarce mainly due to the lack of appropriate separation and analytical methods (Hartmann et al., 2015). According to Boxall et al. (2017), AuNP derived from consumer products are expected to be present in water in concentrations ranging from 100 to $1430 \mathrm{ng} / \mathrm{L}$.

Few studies on the biodistribution and toxicity of AuNP in aquatic organisms have thus far been undertaken. Nevertheless, evidence indicates that AuNP are able to accumulate and induce toxicity to some extent in different trophic levels of the food chain (Gunduz et al., 2017; Lasagna-Reeves et al., 2010; Tedesco et al., 2010). Size, shape, and surface chemistry are known to govern the interaction of AuNP with the biological systems and consequently uptake and biological outcomes (Hornos Carneiro \& Barbosa, 2016). While the role of size and surface charge in AuNP-induced effects was thoroughly addressed (Bozich et al., 2014; Dominguez et al., 2015; Pan et al., 2012; Park et al., 2015; Wray \& Klaine, 2015), the impact of shape has been less investigated. Overall, Au nanospheres were shown to be more efficiently internalized and cytotoxic than $\mathrm{Au}$ nanorods (AuNR) in mammalian cells (Chithrani et al., 2006; Janát-Amsbury et al., 2011; Tarantola et al., 2011). However, a study performed in Daphnia magna, by Wray and Klaine (2015), to establish the influence of size, surface chemistry, and shape for AuNP uptake, and elimination indicated that shape exerted a relatively minor influence on both processes. Moreover, AuNP were found to be transferred between trophic levels through the food chain. Data demonstrated that AuNP were detected in tissues of Daphnia magna fed with the unicellular microorganisms Chlamydomonas reinhardtii and Euglena gracilis previously exposed to these MNM (Lee et al., 2015). Gold nanoparticles were shown to accumulate in the digestive tract of both aquatic invertebrates and fish following exposure to concentrations from 0.5 to $100 \mathrm{mg} / \mathrm{L}$ and $20 \mathrm{mg} / \mathrm{L}$, respectively; however, no apparent adverse effects were observed (Botha et al., 2016; García-Cambero et al., 2013). In contrast, adverse effects of AuNP on aquatic organisms were reported (Pan et al., 2012; Teles et al., 2016). Impaired burrowing speed and increased activity levels of catalase (CAT), superoxide dismutase (SOD), and glutathione S-transferase (GST) were noted in the bivalve Scrobicularia plana exposed to $100 \mu \mathrm{g} / \mathrm{L}$ of differently sized $(5,15$ or $40 \mathrm{~nm}$ ) AuNPs (Pan et al., 2012). Further, exposure to 4,80 , or $1600 \mu \mathrm{g} / \mathrm{L}$ of $40 \mathrm{~nm}$ AuNP capped with polyvinylpyrrolidone (PVP) enhanced hepatic expression of antioxidant, immune, and apoptosis related-genes mRNA levels in the marine teleost Sparus aurata (Teles et al., 2016).

In this context, the aim of this study was to examine the effects of AuNR on early life stages of biota, the most sensitive life cycle stages and often highly predictive of xenobiotics toxicity in the adult stage, by assessing acute and developmental toxicity of a commercial suspension of AuNR stabilized with CTAB (CTAB-AuNR), a commonly used capping agent in colloidal synthesis of AuNR.

Zebrafish embryos were selected since this species is recognized as a suitable and relevant model for ecotoxicological studies, with a high degree of genetic, molecular, and physiological similarity to humans and a good alternative to animal testing (Dai et al., 2014; Dooley \& Zon, 2000; Lima et al., 2015; Lyche et al., 2016; Weber et al., 2015). The Au content of zebrafish embryos exposed to CTABAuNR was measured prior to and shortly after hatching to determine internalization of these NR. Since genotoxic agents induce carcinogenesis and/or heritable defects that may severely impact the health 
of an individual or the population, the genotoxic potential of CTAB-AuNR at sublethal concentrations was also investigated.

\section{Material and methods}

\section{Reagents}

All chemicals used were of highest purity or analytical grade available. Dimethyl sulfoxide (DMSO; CAS no. 37-68-5), Triton X-100 (CAS no. 9002-93-1), low melting point (LMP) agarose (CAS no. 39346-81-1), Tris-HCl (CAS no. 1185-53-1), 30\% (w/v) hydrogen peroxide $\left(\mathrm{H}_{2} \mathrm{O} 2\right.$; CAS no. 7722-84-1) solution, $10 \mathrm{mg} /$ $\mathrm{ml}$ ethidium bromide (CAS no 1239-45-8) solution, and cetyltrimethylammonium bromide (CTAB; CAS no. 57-09-0) were purchased from Sigma-Aldrich (Madrid, Spain). Absolute ethanol (EtOH; CAS no. 64-17-5), sodium hydroxide $(\mathrm{NaOH}$; CAS No. 1310-73-2), sodium chloride (NaCl; CAS no. 7647-14-5), hydrochloric acid ( $\mathrm{HCl}$, CAS no.764701-0), and Tris base (CAS no. 77-86-1) were obtained from Merck (Darmstadt, Germany). Fetal bovine serum (FBS) and Molecular Probes SYBR Gold were purchased from Thermo Fisher Scientific (Madrid, Spain), while ethylenediaminetetraacetic acid disodium salt ( $\mathrm{Na}_{2}$ EDTA; CAS no. 6381-92-6) and nitric acid $\left(\mathrm{HNO}_{3}\right.$; $\mathrm{CAS}$ no. 7697-37-2) were obtained from Prolab (Quebec, Canada). Phosphatebuffered saline (PBS; CAS no. 10049-21-5) and normal melting point (NMP) agarose were supplied by Lonza (Basel, Swiss) and Bioline (London, UK), respectively. A gold pure calibration standard was obtained from Perkin Elmer (Waltham, MA, USA).

\section{Physicochemical characterization of the CTAB-AuNR}

The CTAB-stabilized AuNR (catalogue no. A12-10750 ) with axial dimension $=10 \mathrm{~nm}$, long size dimension $=35 \mathrm{~nm}$, and absorbance peak $=750 \mathrm{~nm}$ were supplied by Nanopartz ${ }^{\mathrm{TM}}$ (Salt Lake City, UT, USA) and stored according to manufacturer's recommendations. Size and morphology of the CTAB-AuNR were assessed by Transmission Electron Microscopy (TEM) either in the stock or in working suspensions using a Hitachi H-9000 microscope operated at 300 $\mathrm{kV}$. For this analysis, a drop of the suspensions under study was placed on a carbon-coated copper $(\mathrm{Cu})$ grid and the solvent was left to evaporate at room temperature. Particle size distribution was measured in TEM images $(n=150 \mathrm{NP})$ using the ImageJ software (NIH, USA). To determine the crystallographic nature and purity of the tested AuNR, a TEM-energy dispersive X-ray (EDX) analysis was performed. Zeta potential was measured by Laser Doppler electrophoresis using a Zetasizer Nano ZS (Malvern Instruments, Worcestershire, UK). Measurements were performed in triplicate, either in distilled water or in zebrafish water $(\mathrm{ZW})$.

\section{Handling and preparation of the CTAB-AuNR suspensions}

All procedures of handling and preparation of the CTAB-AuNR suspensions were standardized to minimize within-experiment variations. The experiments were performed using the same batch of AuNR. The stock suspension was maintained at $4^{\circ}$ $\mathrm{C}$, protected from light and remained stable without any detectable sign of precipitation or change of color throughout the study. Different concentrations of CTAB-AuNR were freshly prepared from the stock suspension by direct dilution in autoclaved ZW.

\section{Zebrafish (Danio rerio) maintenance and embryo collection}

Adult zebrafish (Danio rerio) were maintained under standard controlled conditions $\left(26 \pm 1^{\circ} \mathrm{C}\right.$, $80 \%$ humidity, photoperiod cycle of $16 \mathrm{hr}$ light: $8 \mathrm{hr}$ dark) in tanks equipped with recirculating systems. The fish were fed with a commercially artificial diet (ZM 400 Granular) and maintained in carbon-filtered water with the following characteristics: $0.34 \mathrm{mg} / \mathrm{L}$ of Instant Ocean ${ }^{\circledast}$ synthetic sea salt (Spectrum Brands, USA), $26.0 \pm 1^{\circ} \mathrm{C}, 750 \pm 50$ $\mu \mathrm{S} / \mathrm{cm}, \mathrm{pH} 7.5 \pm 0.5$ and dissolved oxygen saturation $\geq 95 \%$. For the experiments, zebrafish eggs were obtained by natural crossbreeding. Zebrafish eggs were carefully collected within $1 \mathrm{hr}$ after natural mating, rinsed in $\mathrm{ZW}$ and observed under a stereomicroscope (Stereoscopic Zoom Microscope SMZ 1500, Nikon Corporation, Japan). Unfertilized eggs, id est eggs with irregularities during cleavage and eggs with injuries or other kind of malformations, were discarded. 


\section{Acute and developmental toxicity assessment}

To assess the toxicity of CTAB-AuNR on zebrafish embryos, experiments were performed according to the OECD testing guideline (TG) 236 on Fish Embryo Acute Toxicity (FET) Test (Organisation for Economic Cooperation and Development (OECD), 2013). At $6 \mathrm{hr}$ postfertilization (hpf), embryos were exposed to different concentrations of CTAB-AuNR. A toxicity range finding test prior to the definitive toxicity test was conducted to select the appropriate concentrations. The definitive test was conducted to determine the concentration producing $50 \%$ of mortality at $96 \mathrm{hpf}\left(\mathrm{LC}_{50,96 \mathrm{~h}}\right)$. For this test, embryos at 6 hpf were exposed to different concentrations of CTAB-AuNR (50 to $150 \mu \mathrm{g} / \mathrm{L}$ ) and of CTAB (0.008 to $0.017 \mathrm{mM}$, corresponding to the concentrations present in the CTAB-AuNR tested ones). Embryos exposed to $\mathrm{ZW}$ were used as negative controls. Ten embryos were used per replicate, and three replicates were employed per treatment and distributed individually in 24-wells microplates $(2 \mathrm{ml}$ test suspension per well) containing four internal controls. Embryos were observed under a stereomicroscope (Stereoscopic Zoom Microscope SMZ 1500, Nikon Corporation, Japan) at 24, 48, 72, and $96 \mathrm{hpf}$ and the following parameters evaluated: survival, somite formation, incidence of pericardial edema, lack of heartbeat, malformations (general, spinal, tail and head), hatching, total body length (snout to tail tip), and developmental delay. At $48 \mathrm{hpf}$, heart rate (beats/15 sec) was measured by counting heart beats at $26 \pm 1^{\circ} \mathrm{C}$ under a stereomicroscope in three randomly selected embryos of each replicate. The body length was measured in digital images taken from zebrafish newly hatched larvae using the ImageJ software $(\mathrm{NIH}$, USA). To assess developmental delay, embryos were staged as described by Kimmel et al. (1995).

\section{Uptake of CTAB-AuNR by zebrafish embryos}

To investigate the degree of uptake of CTAB-AuNR, zebrafish embryos (6 hpf) were exposed to sublethal concentrations of the CTAB-AuNR $(42,50,60,72$ or $87 \mu \mathrm{g} / \mathrm{L})$. For this analysis, 30 embryos/treatment were used and distributed individually in 24-wells microplates ( $2 \mathrm{ml}$ test suspension per well). Three independent uptake experiments were performed. At the end of the exposure period (48 and $96 \mathrm{hpf}$ ), zebrafish embryos were rinsed twice in $\mathrm{ZW}$ to remove unspecific binding of AuNR. The excess of ZW was removed using a filter paper and embryos weighed. The embryos were stored at $-20^{\circ} \mathrm{C}$ until analysis. The AuNR uptake by zebrafish embryos was estimated based on embryo Au content quantified by Inductively Coupled Plasma-Optical Emission Spectrometry (ICP-OES). The collected samples were transferred into polytetrafluoroethylene (PTFE) vessels and digested in a mixture of

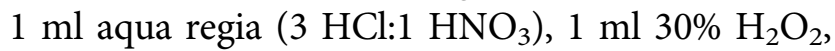
and $6 \mathrm{ml}$ deionized water for $1.5 \mathrm{hr}$ at $220^{\circ} \mathrm{C}, 4$ bar, 1200 watts using an Ethos Advanced Microwave Digestion System (Milestone, Bergamo, Italy). After cooling, the samples were diluted in deionized water to a final volume of $6 \mathrm{ml}$. Samples were injected in an iCAP 7000 ICP optical emission spectrometer (Thermo Fisher Scientific, Cambridge, England) equipped with an CETAC ASX520 autosampler and total elemental Au quantified (axial mode, wavelength 242.795, exposure time $15 \mathrm{sec}$ ) using an 8point standard curve $(1.65-200 \mu \mathrm{g} / \mathrm{L})$. To estimate the digestion and recovery efficiency, unexposed embryos were spiked with known concentrations $(12.5,25$ or $50 \mu \mathrm{g} / \mathrm{L})$ of $\mathrm{Au}$ standard or CTAB$\mathrm{AuNR}$ and $\mathrm{Au}$ content of digested samples quantified.

\section{Genotoxicity assessment}

Single cell gel electrophoresis assay (Comet assay) was performed to assess the ability of CTAB-AuNR to produce DNA damage in zebrafish embryos. For this analysis, 25 embryos (6 hpf) were used and distributed individually in 24-wells microplates ( $2 \mathrm{ml}$ test suspension per well). Zebrafish embryos were exposed to subtoxic concentrations of CTABAuNR (72, 87 or $104 \mu \mathrm{g} / \mathrm{L})$. Embryos exposed to $100 \mathrm{mM}$ of $\mathrm{H}_{2} \mathrm{O}_{2}$ for $10 \mathrm{~min}$ were used as a positive control. Embryo cells were isolated as previously described (Kosmehl et al., 2006), with minor modifications. Briefly, at the end of the exposure period (48 or $96 \mathrm{hpf}$ ), zebrafish embryos were rinsed with PBS pH 7.4, transferred to flat microcentrifuge tubes, and homogenized in $100 \mu \mathrm{PBS}$ pH 7.4 with a pestle. The cell suspensions were then filtered through a 70 $\mu \mathrm{m}$ strainer in order to separate the individual cells from the remaining macerated tissues and centrifuged at $300 \times \mathrm{g}, 5 \mathrm{~min}, 4^{\circ} \mathrm{C}$. The pellets were 
resuspended in $200 \mu \mathrm{l}$ ice-cold freezing medium (FBS with $10 \%$ DMSO) and stored at $-80^{\circ} \mathrm{C}$ until analysis.

The comet assay was carried out under alkaline conditions following the procedure developed by Singh et al. (1988) with some modifications. Briefly, cell suspensions were thawed and centrifuged at $300 \times \mathrm{g}, 5 \mathrm{~min}, 4^{\circ} \mathrm{C}$. The resulting pellets were resuspended in $\mathrm{PBS} \mathrm{pH} 7.4$ and subjected to another centrifugation at $400 \times \mathrm{g}, 5 \mathrm{~min}, 4^{\circ} \mathrm{C}$. The resulting pellets were mixed in $100 \mu \mathrm{l} \%$ (w/v) LMP agarose and layered onto dry microscope slides (VWR, Darmstadt, Germany) pre-coated with 1\% NMP agarose. After gel solidification at $4^{\circ} \mathrm{C}$, slides were placed in a Coplin jar and immersed in ice-cold lysis solution (2.5 M NaCl, $100 \mathrm{mM} \mathrm{Na} 2$ EDTA, $10 \mathrm{mM}$ Tris-base, $10 \mathrm{M} \mathrm{NaOH}, \mathrm{pH} 10$, supplemented with $1 \%$ Triton-X 100 and $10 \%$ DMSO) for $1.5 \mathrm{hr}$ at $4^{\circ} \mathrm{C}$, protected from light to lyse the cells and separate DNA from histones. For unwinding of DNA, all slides were immersed in freshly prepared electrophoresis buffer $(200 \mathrm{mM}$ $\mathrm{Na}_{2}$ EDTA, $0.3 \mathrm{M} \mathrm{NaOH} \mathrm{pH}>13$ ) in the electrophoresis unit for $20 \mathrm{~min}$ at $4^{\circ} \mathrm{C}$, followed by electrophoresis for $15 \mathrm{~min}$ at $25 \mathrm{~V}$ and $300 \mathrm{~mA}$. The slides were then neutralized with $0.4 \mathrm{M}$ Tris base $\mathrm{pH} 7.5$ followed by fixation with $\mathrm{EtOH} 70 \%$ and $96 \%$ for 15 min each at room temperature. After air-drying the slides overnight, DNA was stained with a $20 \mu \mathrm{g} / \mathrm{ml}$ ethidium bromide solution. The slides were coded, and one scorer performed the comet analysis using a fluorescence microscope (Nikon Eclipse E400 microscope attached to an epifluorescence illuminator Nikon C-SHG1) with $500 \times$ magnification and the image analysis software Comet Assay IV (Perceptive Instruments, Suffolk, UK). The \% DNA in the comet tail and the olive tail moment was utilized as a measure of the amount of DNA damage. One hundred cells per slide (50 for each replicate gel) were counted, and three independent experiments were performed in triplicate.

\section{Statistical analysis}

Data are expressed as mean \pm standard error of the mean (SEM). Statistical and nonlinear regression analyses were performed using the GraphPad Prism 6 software (La Jolla, CA, USA). Median lethal concentration $\left(\mathrm{LC}_{50,96 \mathrm{~h}}\right)$ was calculated by fitting concentration-response curves with a sigmoidal nonlinear regression. Parametric analyzes were performed using one-way ANOVA followed by the multiple comparison Dunnett's post hoc test to compare each tested concentration with the control. Non-parametric analysis of genotoxicity data was performed using Kruskal-Wallis followed by the multiple comparisons post hoc Dunn's test to determine significant differences relative to control. Significance was set at $p<0.05$.

\section{Results}

\section{Physicochemical characterization of CTAB-AuNR}

The monitored physicochemical characteristics of the CTAB-AuNR stock suspension used in the present study are summarized in Table 1. TEM analysis revealed high monodispersity and well-defined rod-like shape of CTAB-AuNR (Figure 1A and 1B). Figure $1 \mathrm{C}$ illustrates the $\mathrm{X}$-ray diffraction pattern of the CTAB-AuNR, which is consistent with metallic $\mathrm{Au}$. The corresponding TEM size distribution histograms (Figure 1D) show particles with a mean length and diameter of $19.96 \pm 0.46 \mathrm{~nm}$ and $7.41 \pm 0.11 \mathrm{~nm}$, respectively, while zeta potential was $69.9 \pm 14.8 \mathrm{mV}$ (Table 1). The EDX spectrum depicted in Figure 1E confirms the purity of the stock suspension under evaluation as only peaks of $\mathrm{Au}$ and $\mathrm{Cu}$ were detected, the latter arising from the grid used in the analysis. When comparing physicochemical characterization data of CTAB-AuNR obtained in this investigation with values provided by the manufacturer, some differences were observed such as small reduction in the $\mathrm{Au}$ concentration and size (length and diameter) of the CTAB-AuNR as well as an increase in zeta potential, as presented in Table 1.

Table 1. Summary of the main physicochemical features of the CTAB-AuNR stock suspension.

\begin{tabular}{lcc}
\hline & $\begin{array}{c}\text { Manufacturer's } \\
\text { measurements }\end{array}$ & $\begin{array}{c}\text { Performed } \\
\text { measurements }\end{array}$ \\
\hline${\text { Length }(\mathbf{n m})^{\text {a) }}}_{\text {Diameter }(\mathbf{n m})}{ }^{\text {a) }}$ & 35 & $19.96 \pm 0.46$ \\
Zeta potential $(\mathbf{m V})^{\text {b) }}$ & 10 & $7.41 \pm 0.11$ \\
${\text { [Au] }(\boldsymbol{\mu g} / \mathbf{m L})^{\mathbf{c})}}$ & 40 & $69.90 \pm 14.80$ \\
\hline
\end{tabular}

Dimensions (length and diameter) were determined by TEM. Results are expressed as mean \pm SEM $(n=150 \mathrm{NPs})$;

Zeta potential was measured by Laser Doppler electrophoresis. Results are expressed as mean \pm SD $(n=3)$;

Concentration of $\mathrm{Au}$ in the colloidal suspension was determined by ICPOES. 


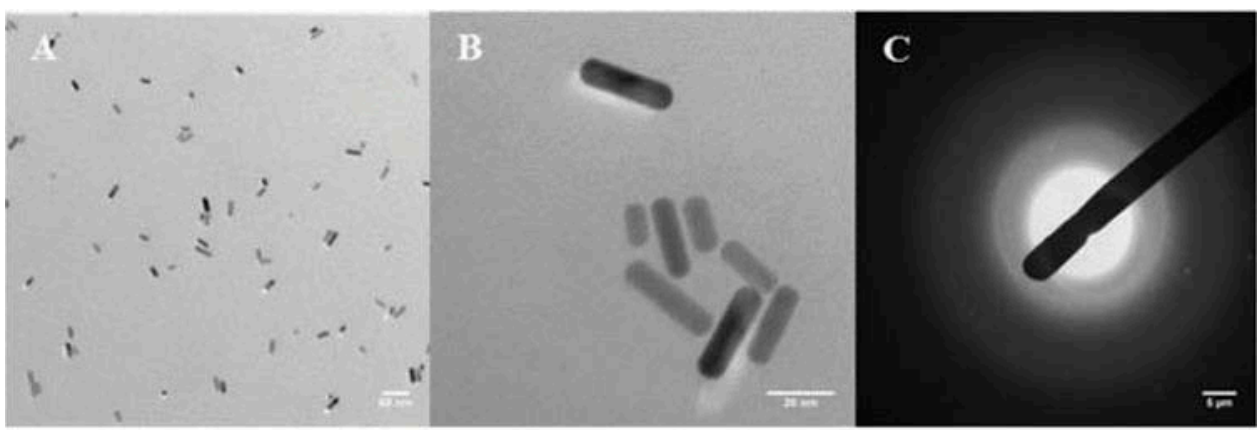

D
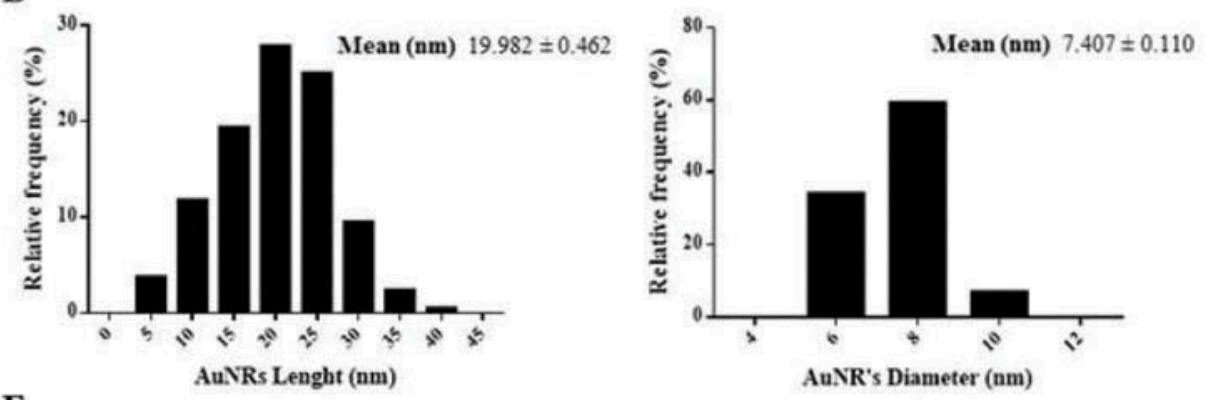

E



Figure 1. Transmission Electron Microscopy (TEM) analysis of NanoPartz ${ }^{\text {TM }}$ CTAB-AuNR. Representative (A) low- (30,000x) and (B) high-magnification (200,000x) images, (C) X-ray diffraction pattern, (D) histograms of particle size distribution, and (E) EDX spectrum of CTAB-AuNR stock suspension. Particle size values are mean \pm SEM; scale bars: $50 \mathrm{~nm}(\mathrm{~A}), 20 \mathrm{~nm}(\mathrm{~B})$ and $5 \mu \mathrm{m}(\mathrm{C})$.

To evaluate how dispersion of CTAB-AuNR in ZW might alter the initial characteristics of CTABstabilized AuNP, size and zeta potential measurements were also performed in the working suspensions. The TEM images of CTAB-AuNR after dispersion in $\mathrm{ZW}$ revealed aggregation/agglomeration of the AuNR in ZW, particularly at high concentrations such as $104 \mu \mathrm{g} / \mathrm{L}$ (Figure 2A) and $150 \mu \mathrm{g} / \mathrm{L}$ (Figure 2B), when compared to highly monodispersed AuNR stock suspension (Figure 1A). In addition, as presented in Table 2, dispersion of CTAB-AuNR in ZW produced an inversion in the original electrostatic potential from positive to negative at all concentrations tested with values ranging from -2.8 to $-26.2 \mathrm{mV}$.

\section{Lethality and developmental effects of CTAB-AuNR}

Lethality of CTAB-AuNR to zebrafish embryos was investigated following the OECD TG 236 guidelines. A preliminary range finding test showed $100 \%$ mortality of zebrafish embryos exposed to CTAB-AuNR at concentrations $\geq 185 \mu \mathrm{g} / \mathrm{L}$ for $24 \mathrm{hpf}$ (data not shown). A definitive test was performed at a lower concentration range $(50,60,72,87,104,125$, or $150 \mu \mathrm{g} / \mathrm{L})$. At $24 \mathrm{hpf}$, embryos exposed to CTAB- 


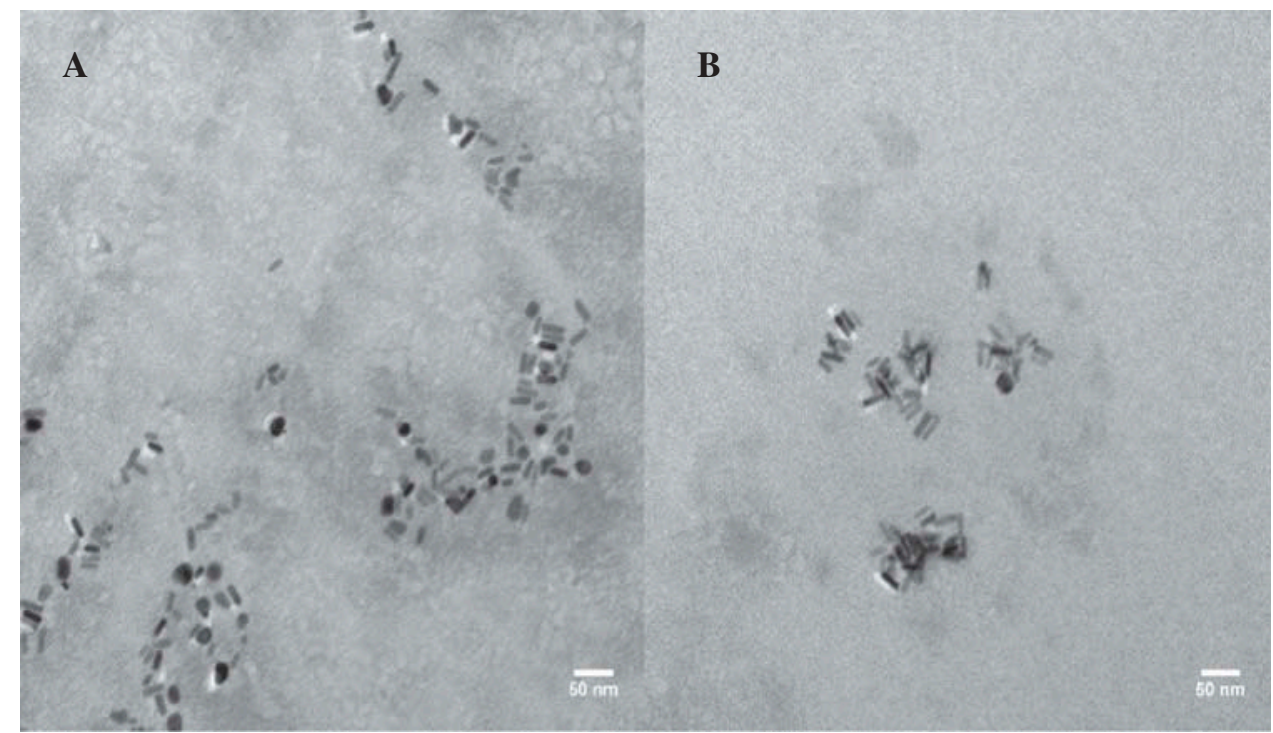

Figure 2. Representative TEM micrographs (60,000x magnification) of the CTAB-AuNR tested suspensions dispersed in zebrafish water $(\mathrm{ZW})$ at $104 \mu \mathrm{g} / \mathrm{L}(\mathrm{A})$ and $150 \mu \mathrm{g} / \mathrm{L}$ (B). Scale bars: $50 \mathrm{~nm}$.

Table 2. Zeta potential of CTAB-AuNR tested suspensions dispersed in zebrafish water.

\begin{tabular}{lc}
\hline$[C T A B-A u N R](\mu \mathrm{g} / \mathrm{L})$ & Zeta Potential $(\mathrm{mV})$ \\
\hline $\mathbf{6 0}$ & $-23.0 \pm 2.2$ \\
$\mathbf{7 2}$ & $-26.2 \pm 2.2$ \\
$\mathbf{8 7}$ & $-2.8 \pm 4.6$ \\
$\mathbf{1 0 4}$ & $-4.3 \pm 2.7$ \\
$\mathbf{1 2 5}$ & $-23.0 \pm 3.8$ \\
$\mathbf{1 5 0}$ & $-14.6 \pm 3.0$ \\
\hline
\end{tabular}

Zeta potential was measured by Laser Doppler electrophoresis. Results are expressed as mean \pm SD $(n=3)$.

AuNR highest tested concentrations, 125 and $150 \mu \mathrm{g} /$ L, exhibited a mortality rate of 67 and $73 \%$, respectively (Table 3). At $96 \mathrm{hpf}$, the cumulative mortality rate of embryos exposed to these concentrations increased up to $100 \%$. Moreover, at lower concentrations tested, the cumulative mortality at $96 \mathrm{hpf}$ was found to be $\leq 10 \%$. Analysis of the cumulative mortality concentration-response curves at $96 \mathrm{hpf}$ revealed a median lethal concentration $\left(\mathrm{LC}_{50,96 \mathrm{~h}}\right)$ of $110.2 \mu \mathrm{g} / \mathrm{L}$ (95\% confidence interval: 100.6-122.8 $\mu \mathrm{g} / \mathrm{L}$ ).

The influence of CTAB-AuNR on developmental parameters in zebrafish embryos throughout the exposure period is summarized in Table 4 . At 24 hpf, detachment of the tail, formation of somites, and eye and brain formation were visible in control (non-exposed) zebrafish embryos (Figure 3A). Further, embryos exposed to concentrations of CTAB-AuNR between 50 and $87 \mu \mathrm{g} / \mathrm{L}$ did not exhibited any marked alterations in these morphological structures. In contrast, CTAB-AuNR at 104, 125, or
Table 3. Mortality (\%) of zebrafish embryos exposed to CTABAuNR.

\begin{tabular}{lcccc}
\hline $\begin{array}{l}\text { [CTAB-AuNR }] \\
(\mu \mathrm{g} / \mathrm{L})\end{array}$ & $24 \mathrm{hpf}$ & $48 \mathrm{hpf}$ & $\mathbf{7 2} \mathrm{hpf}$ & $96 \mathrm{hpf}$ \\
\hline $\mathbf{0}$ & 0 & 0 & 0 & 0 \\
$\mathbf{5 0}$ & 0 & 0 & 0 & 0 \\
$\mathbf{6 0}$ & 0 & 0 & 0 & 0 \\
$\mathbf{7 2}$ & 0 & 0 & 0 & 0 \\
$\mathbf{8 7}$ & $7 \pm 8.9$ & $7 \pm 8.9$ & $7 \pm 8.9$ & $10 \pm 13.3$ \\
$\mathbf{1 0 4}$ & $10 \pm 13.3$ & $10 \pm 13.3$ & $10 \pm 13.3$ & $10 \pm 13.3$ \\
$\mathbf{1 2 5}$ & $67 \pm 4.4$ & $77 \pm 4.4$ & $87 \pm 13.3$ & 100 \\
$\mathbf{1 5 0}$ & $73 \pm 17.7$ & $87 \pm 8.9$ & $87 \pm 8.9$ & $97 \pm 4.4$ \\
\hline
\end{tabular}

Values are mean \pm SD $(n=10)$.

$150 \mu \mathrm{g} / \mathrm{L}$ induced several developmental malformations in exposed embryos, namely tail deformities (e.g., neither posterior elongation of the yolk sac to form the yolk extension nor elongation of the tail bud), abnormal yolk sac and edema, and also a delay in development of the eye and head (Table 4 and Figure 3). The onset of pigmentation in the eyes and body of zebrafish embryos normally occurs between 24 and 48 hpf; however, 26, 86, and 75\% of embryos exposed to 104 (Figure 3F), 125 (Figure 3G), and $150 \mu \mathrm{g} / \mathrm{L}$ (Figure $3 \mathrm{H}$ ) of CTAB-AuNR, respectively, demonstrated decreased pigmentation compared to controls (Figure 3E). At $48 \mathrm{hpf}$, the heart rate was measured, and results are presented in Table 4. Embryos exposed to CTAB-AuNR concentrations $\leq 104 \mu \mathrm{g} / \mathrm{L}$ did not exhibit any significant variation in this parameter, while at the highest concentrations, a marked reduction in the heart rate of the few living 
Table 4. Effects of CTAB-AuNR exposure on zebrafish embryonic development.

\begin{tabular}{|c|c|c|c|c|c|c|c|c|c|c|}
\hline \multirow[b]{2}{*}{$\begin{array}{l}\text { [CTAB- } \\
\text { AuNR] } \\
(\mu \mathrm{g} / \mathrm{L})\end{array}$} & \multicolumn{10}{|c|}{ Alterations (\%) } \\
\hline & $\begin{array}{c}\text { Delayed eye/ } \\
\text { head } \\
\text { development } \\
(24 \mathrm{hpf})\end{array}$ & $\begin{array}{c}\text { Abnormal } \\
\text { eye/head } \\
(24 \mathrm{hpf})\end{array}$ & $\begin{array}{l}\text { Abnormal } \\
\text { tail ( } 24 \\
\text { hpf) }\end{array}$ & $\begin{array}{c}\text { Abnormal } \\
\text { yolk sac } \\
(24 \mathrm{hpf})\end{array}$ & $\begin{array}{c}\text { Edema } \\
(24 \\
\text { hpf })\end{array}$ & $\begin{array}{l}\text { Hypopigmentation } \\
\text { (48 hpf) }\end{array}$ & $\begin{array}{l}\text { Pericardial } \\
\text { edema ( } 96 \\
\text { hpf) }\end{array}$ & $\begin{array}{c}\text { Tail } \\
\text { deformity } \\
\text { (96 hpf) }\end{array}$ & $\begin{array}{l}\text { Heart rate } \\
\text { (beats/min) } \\
(48 \mathrm{hpf})\end{array}$ & $\begin{array}{c}\text { Body } \\
\text { length } \\
(\mathrm{mm})(96 \\
\mathrm{hpf})\end{array}$ \\
\hline 0 & 0 & 0 & 0 & 0 & 0 & 0 & 0 & 0 & $172.9 \pm 2.2$ & $3.8 \pm 0.03$ \\
\hline 50 & 0 & 0 & 0 & 0 & 0 & 0 & 0 & 0 & $167.1 \pm 3.0$ & $3.8 \pm 0.02$ \\
\hline 60 & 0 & 0 & 0 & 0 & 0 & 0 & 0 & 0 & $175.1 \pm 2.0$ & $3.8 \pm 0.03$ \\
\hline 72 & 0 & 0 & 0 & 0 & 0 & 0 & 3.33 & 3.33 & $172.9 \pm 2.0$ & $3.6 \pm 0.03^{*}$ \\
\hline 87 & 0 & 0 & 0 & 3 & 0 & 0 & 0 & 0 & $175.6 \pm 2.0$ & $3.7 \pm 0.04$ \\
\hline 104 & 30 & 0 & 22 & 41 & 22 & 26 & 11.11 & 14.8 & $159.0 \pm 3.4$ & $3.6 \pm 0.04^{*}$ \\
\hline 125 & 0 & 70 & 90 & 70 & 30 & 86 & n.d. & n.d. & - & n.d. \\
\hline 150 & 0 & 75 & 75 & 63 & 13 & 75 & n.d. & n.d. & - & n.d. \\
\hline
\end{tabular}

n.d.- Not determined. All exposed embryos were dead. Values are mean \pm SEM. Data were analyzed by one-way analysis of variance (ANOVA) followed by Dunnett's post hoc test. ${ }^{*} p<0.05$ vs. control.

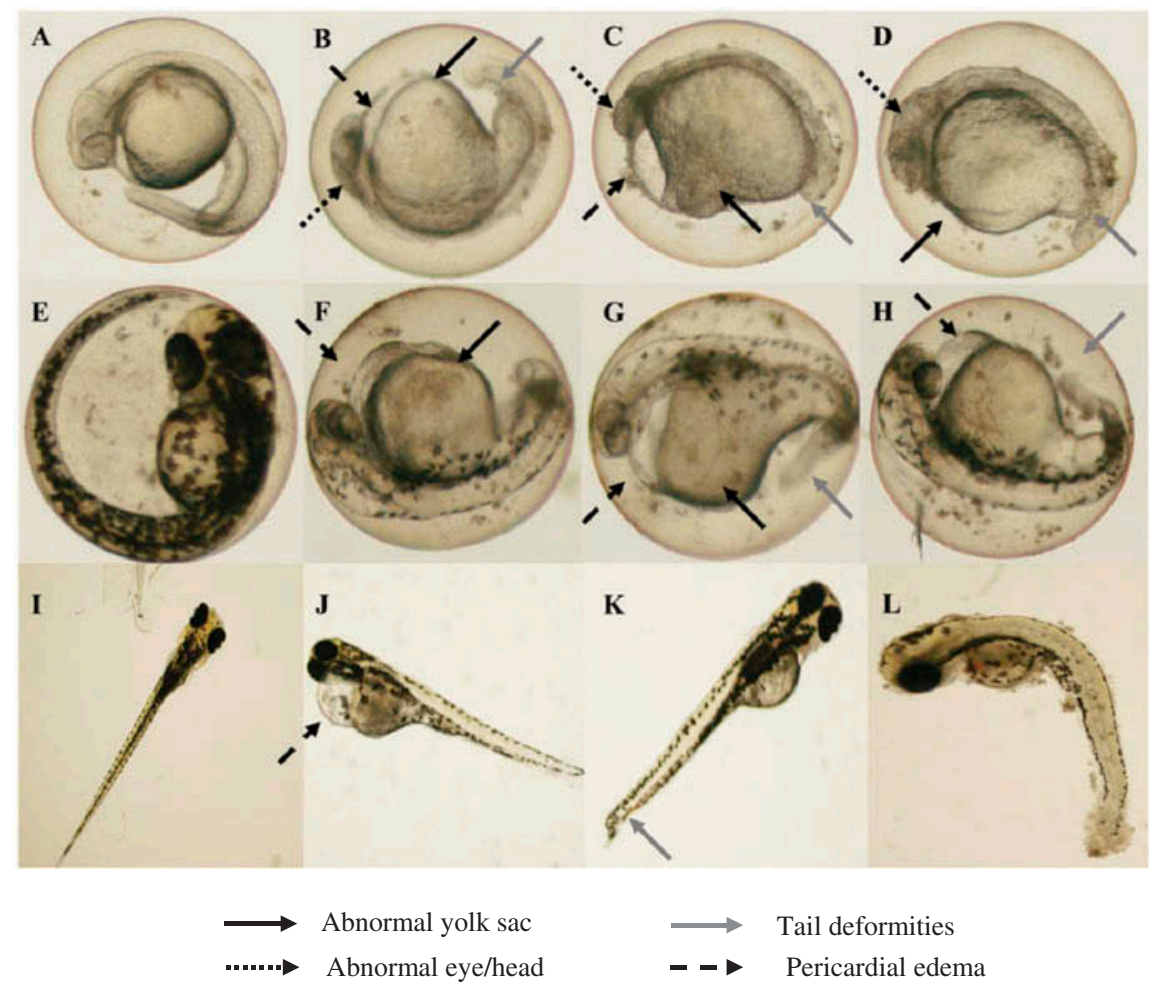

Figure 3. Morphological abnormalities of zebrafish embryos exposed to CTAB-AuNR. At 24 hpf: control embryos (A) and embryos exposed to $104 \mu \mathrm{g} / \mathrm{L}$ (B), $125 \mu \mathrm{g} / \mathrm{L}$ (C) and $150 \mu \mathrm{g} / \mathrm{L}$ (D). At $48 \mathrm{hpf}$ : control embryos (E) and embryos exposed to $104 \mu \mathrm{g} / \mathrm{L}$ (F), $125 \mu \mathrm{g} /$ $\mathrm{L}(\mathrm{G})$ and $150 \mu \mathrm{g} / \mathrm{L}(\mathrm{H})$. At $96 \mathrm{hpf}$ : control embryos (I), embryos exposed to $104 \mu \mathrm{g} / \mathrm{L}$ (J and K), dead embryo (L).

embryos was noted (data not shown). In addition, anomalies in other developmental parameters such as hatching rate, which occurs between 48 and 72 hpf for all tested concentrations (except at the highest one for which more than $95 \%$ mortality was observed just after $24 \mathrm{hr}$ exposure), swim bladder inflation, protrusion of mouth, and pectoral fin formation were not detected. As depicted in Figure 3, developmental abnormalities detected at 24 and $48 \mathrm{hpf}$ were more severe in embryos exposed to 125 or $150 \mu \mathrm{g} / \mathrm{L}$
(Figure 3C, 3G and 3D, 3H, respectively) than in embryos exposed to $104 \mu \mathrm{g} / \mathrm{L}$ CTAB-AuNR (Figure 3B and 3F). All embryos exposed to the two highest concentrations ultimately died within the period of exposure (Figure 3L), whereas for embryos exposed to $104 \mu \mathrm{g} / \mathrm{L}$, a delay in eye and head development, elongation of the tail, and the onset of pigmentation were observed. However, at $96 \mathrm{hpf}$, the anatomy of the eye and head and pigmentation of these embryos did not differ markedly from control as 




Figure 4. Zebrafish embryos (6 hpf) exposed to CTAB. Micrographs of (A) control (non-exposed) and (B) embryos exposed to $0.017 \mathrm{mM} C T A B$, which corresponds to the CTAB concentration present at the highest tested CTAB-AuNR suspension (150 $\mu \mathrm{g} / \mathrm{L})$.

represented in the chronological sequence of Figure 3B, 3F and 3J, which show the same individual at 24, 48, and $96 \mathrm{hpf}$, respectively. Nevertheless, $22 \%$ of zebrafish embryos exposed to $104 \mu \mathrm{g} / \mathrm{L}$ still displayed pericardial edema and/or tail deformities at 96 hpf (Figure 3J and 3K). Further, a reduction of zebrafish body length corresponding to a maximum effect of $6 \%$ was found following exposure to 72,87 , or $104 \mu \mathrm{g} / \mathrm{L}$. However, this decrease was significant only in zebrafish exposed to 72 or $104 \mu \mathrm{g} / \mathrm{L}$ of CTAB-AuNR compared with control (Table 4). Overall, CTAB-AuNR induced an all-or-nothing effect on zebrafish embryos, which did not exhibit severe malformations following exposure to sublethal concentrations of 50 or $60 \mu \mathrm{g} / \mathrm{L}$.

The AuNR tested are capped with CTAB, which was noted to be toxic at high concentrations. Since $\mathrm{CTAB}$ is present in the AuNR stock suspension at a considerable concentration ( $4 \mathrm{mM})$, either adsorption to the surface of the AuNR or freely dispersed in solution, parallel experiments were conducted to assess its toxicity to zebrafish embryos at the same concentration present in the tested CTAB-AuNR suspensions (0.008-0.017 mM). For all tested concentrations, CTAB induced $100 \%$ embryo mortality within $30 \mathrm{~min}$ of exposure. As illustrated in Figure 4B, the membranes of exposed embryos were rapidly disrupted in the presence of CTAB, producing coagulation.

\section{Uptake of CTAB-AuNR by zebrafish embryos}

The uptake of CTAB-AuNR was estimated in unhatched zebrafish embryos exposed to sublethal concentrations $(42-87 \mu \mathrm{g} / \mathrm{L})$ based upon the embryo $\mathrm{Au}$ content determined by ICP-OES before (48 hpf) and after ( $96 \mathrm{hpf}$ ) hatching. The CTAB-AuNP spike-recovery experiments confirmed that embryo digestion procedure was effective and no significant loss of elemental $\mathrm{Au}$ occurred throughout the process until sample injection. Recovery efficiency (\%) values were close to $100 \%$, varying from $123.49 \pm 3.78$ to $104.72 \pm 0.04 \%$.

As shown in Figure 5, a concentration-dependent AuNR embryo accumulation trend was observed at both assessed time points. Elemental $\mathrm{Au}$ was detected in embryos exposed to CTAB-AuNR, at both 48 and $96 \mathrm{hpf}$, with values ranging from $0.24 \pm 0.06$ to $1.02 \pm 0.27 \mu \mathrm{g} \mathrm{Au} / \mathrm{g}$ fresh weight and from $0.02 \pm 0.02$ to $2.41 \pm 0.77 \mu \mathrm{g} \mathrm{Au} / \mathrm{g}$ fresh weight, respectively. As expected, Au was not found in control samples (i.e., non-exposed zebrafish embryos) (data not shown). In terms of \% of initial administered concentration, the amount of $\mathrm{Au}$ found in zebrafish embryos exposed to CTAB-AuNR, either before (48 hpf) or after hatching (96 hpf), corresponds to less than $0.6 \%$ of the initial tested concentration (Table 5). 


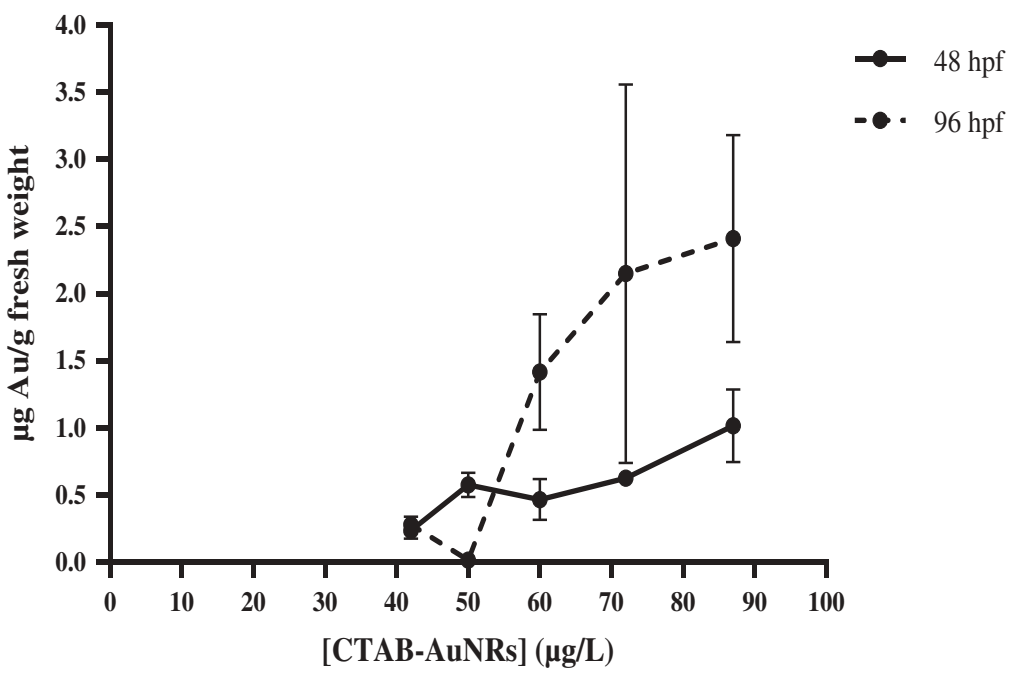

Figure 5. Au content of embryos exposed to different concentrations of CTAB-AuNR at 48 and 96 hpf as assessed by ICP-OES. Data are expressed as $\mu \mathrm{g} \mathrm{Au/g}$ fresh weight. Values are mean $\pm \mathrm{SEM}(n=3)$.

Table 5. Fraction of elemental Au found in zebrafish embryos comparing to the initial concentration of CTAB-AuNR in media expressed as percentage (\%) of uptake.

\begin{tabular}{lcc}
\hline \multirow{2}{*}{$\begin{array}{l}\text { [CTAB-AuNR] } \\
\mu \mathrm{g} / \mathrm{L})\end{array}$} & \multicolumn{2}{c}{ Uptake (\%) } \\
\cline { 2 - 3 } & $48 \mathrm{hpf}$ & $96 \mathrm{hpf}$ \\
\hline 42 & $0.29 \pm 0.11$ & $0.13 \pm 0.08$ \\
50 & $0.55 \pm 0.04$ & $0.01 \pm 0.01$ \\
60 & $0.26 \pm 0.05$ & $0.40 \pm 0.10$ \\
72 & $0.51 \pm 0.17$ & $0.44 \pm 0.30$ \\
87 & $0.49 \pm 0.16$ & $0.49 \pm 0.22$ \\
\hline
\end{tabular}

Data represent the mean \pm SEM of three independent experiments.

\section{Genotoxicity assessment}

The genotoxic potential of CTAB-AuNR was assessed utilizing the Comet assay. As presented in Table 6, exposure of early life stages of zebrafish to CTAB-AuNR did not induce significant DNA damage in embryos cells both at 48 and $96 \mathrm{hpf}$. Although embryos exposed to 72 and $87 \mu \mathrm{g} / \mathrm{L}$ showed a numerical rise in tail intensity and tail moment at $48 \mathrm{hpf}$, there were no marked differences compared to controls. Zebrafish embryos exposed to $100 \mathrm{mM} \mathrm{H}_{2} \mathrm{O} 2$ for $10 \mathrm{~min}$ (positive control) exhibited significant DNA damage as noted in Figure 6E, with tail intensity and tail moment values of 83 and $21 \%$, respectively.

\section{Discussion}

A comprehensive physicochemical characterization of MNM is a crucial step toward understanding how biological media and dispersion protocols might influence their original properties but also for
Table 6. Comet assay analysis of DNA damage in zebrafish embryos exposed to CTAB-AuNR at 48 and $96 \mathrm{hpf}$.

\begin{tabular}{ccc}
\hline & Tail intensity (\%) & Tail moment \\
\hline $\mathbf{4 8} \mathbf{~ h p f}$ & & \\
Control & $13.17 \pm 1.01$ & $1.30 \pm 0.126$ \\
$72 \mu \mathrm{g} / \mathrm{L}$ & $15.39 \pm 5.17$ & $1.66 \pm 0.604$ \\
$87 \mu \mathrm{g} / \mathrm{L}$ & $17.04 \pm 1.14$ & $1.72 \pm 0.231$ \\
$104 \mu \mathrm{g} / \mathrm{L}$ & $12.88 \pm 2.40$ & $1.25 \pm 0.238$ \\
$\mathbf{9 6} \mathbf{~ h f}$ & & \\
$\mathrm{Control}$ & $11.24 \pm 1.81$ & $1.10 \pm 0.232$ \\
$72 \mu \mathrm{g} / \mathrm{L}$ & $11.43 \pm 2.40$ & $0.98 \pm 0.219$ \\
$87 \mu \mathrm{g} / \mathrm{L}$ & $10.94 \pm 1.51$ & $0.96 \pm 0.152$ \\
$104 \mu \mathrm{g} / \mathrm{L}$ & $11.61 \pm 1.17$ & $1.14 \pm 0.041$ \\
\hline
\end{tabular}

Data represent the mean \pm SEM of three independent experiments.

interpreting toxicity data, as MNM behave in media including aggregation/agglomeration, and sedimentation and their interaction with biological systems are highly dependent on their chemical composition, particle size, morphology, and surface chemistry (Gatoo et al., 2014; Hartmann et al., 2015; Kermanizadeh et al., 2016; Luyts et al., 2013). In the present study, CTAB-AuNR were characterized either in the stock suspension or after dispersion in ZW. In the stock suspension, our results revealed high-pure, monodisperse and positively charged CTAB-AuNR. These findings confirm that $\mathrm{CTAB}$ acts as an effective stabilizing agent conferring a high positive electrostatic potential to AuNR. However, differences in all parameters measured were observed when comparing with physicochemical characteristics provided by the manufacturer, which highlights the need for a complete NP characterization, a step that is not always conducted in ecotoxicological studies that often rely 

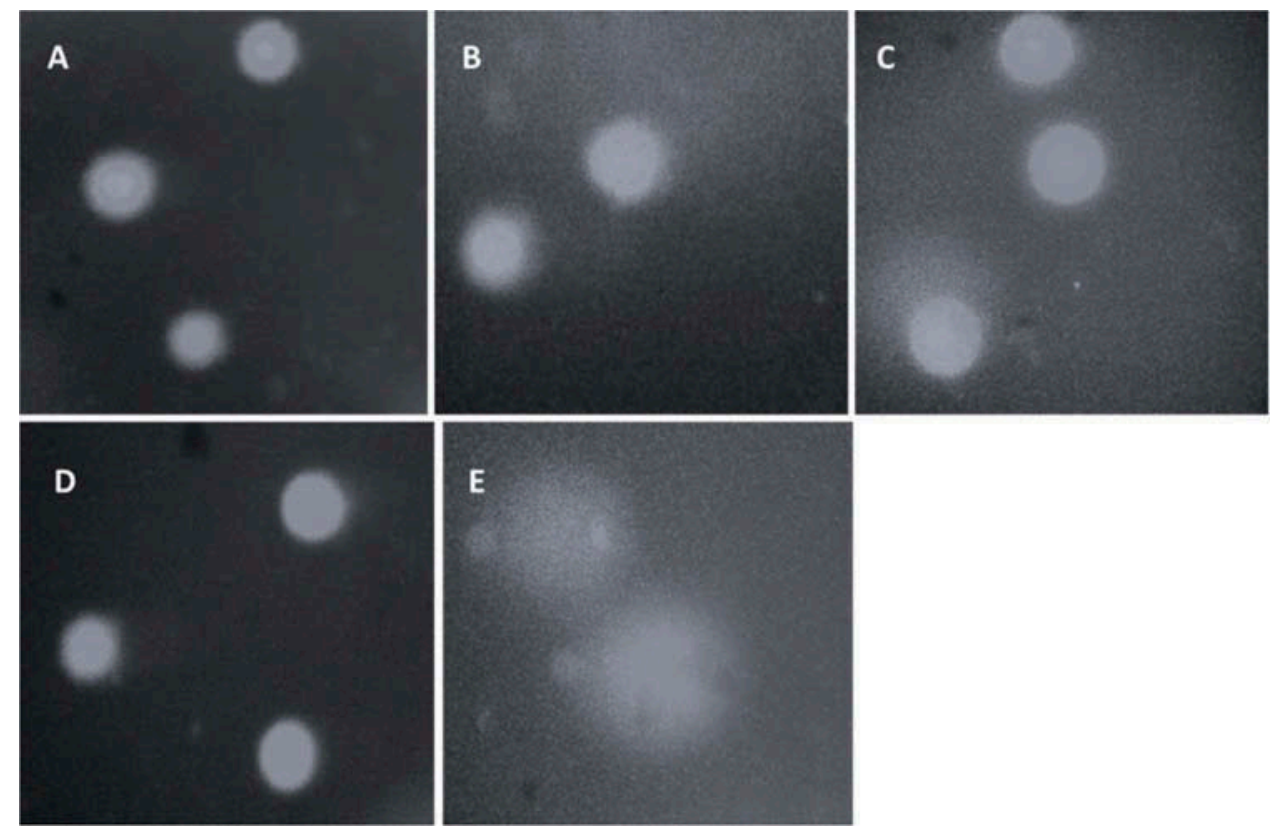

Figure 6. Representative images of the comet assay in zebrafish embryo cells at $48 \mathrm{hpf}$ following exposure to 0 (control) (A), 72 (B), 87 (C), 104 (D) $\mu \mathrm{g} / \mathrm{mL}$ of CTAB-AuNR. Control, and CTAB AuNR-treated embryos exhibit residual to no tail. The embryos exposed to $100 \mathrm{mM} \mathrm{H}_{2} \mathrm{O}_{2}$ (positive control) (D), a DNA damaging agent, showed a long tail.

on the manufacturer's analysis. After dispersion in ZW, a positive-to-negative shift in the zeta potential of CTAB-AuNR, with mean values ranging from -2.8 to $-26.2 \mathrm{mV}$, was detected. Zeta potential is a measure of the stability of colloidal suspensions as this parameter is highly dependent on physicochemical characteristics of the dispersion media such as ionic strength, ionic composition, and $\mathrm{pH}$. Hence, the high ionic strength of the ZW (conductivity $=750$ $\mu \mathrm{S} / \mathrm{cm}$ ) may impart high instability to CTAB-AuNR dispersions resulting in formation of agglomerates/ aggregates, the presence of which was confirmed in the TEM images.

This aggregation phenomenon was previously reported for other types of NP such as $\mathrm{Fe}_{2} \mathrm{O} 3$, $\mathrm{TiO}_{2}, \mathrm{Ag}$, and $\mathrm{ZnO}$ (Asharani et al., 2008; Fang et al., 2015; Zhu et al., 2012, 2009). Once released into the aquatic environment, these NP aggregates/ agglomerates are likely to settle out and deposit into the sediments rather than remaining suspended along the water column. Thus, zebrafish embryos constitute a relevant model to assess ecological effects of NP aggregates/agglomerates since these are demersal, which facilitates extrapolation from lab to field conditions. Moreover, previous studies reported that aggregation/agglomeration state may be an important determinant of NP-mediated toxicity as this affects NP uptake and bioavailability and consequently leads to different biological outcomes (Albanese \& Chan, 2011; Wong et al., 2010). Fang et al. (2015) showed that increasing the levels of humic acid or ionic strength in the environment influence $\mathrm{TiO}_{2}$ NP-initiated toxicity to zebrafish since elevated $\mathrm{TiO}_{2} \mathrm{NP}$ aggregate formation, in the exposure media, decreased bioavailability to zebrafish.

In the present study, early life stages of zebrafish were exposed to CTAB-AuNR concentrations between 50 and $150 \mu \mathrm{g} / \mathrm{L}$, and embryonic development and lethality were analyzed. Under our experimental conditions, $\mathrm{LC}_{50}$ mean value of CTAB-AuNR obtained for embryos at $96 \mathrm{hpf}$ was $110.2 \mu \mathrm{g} / \mathrm{L}$. Recently Galindo (2014) demonstrated that CTABAuNR suspensions were more toxic to the rotifer Brachionus calyciflorus $\left(\mathrm{LC}_{50}=51 \mu \mathrm{g} / \mathrm{L}\right)$ or to neonates of two species of cladocerans, Daphnia magna and Daphnia longispina $\left(\mathrm{LC}_{50}=3.39\right.$ and $4.43 \mu \mathrm{g} / \mathrm{L}$, respectively), compared with zebrafish embryos. These findings support the view that different species may exhibit differential sensitivity when exposed to the same NP. Similar observations were previously reported for three species of Daphnia, where Daphnia magna was found to be more tolerant than Daphnia pulex or Daphnia galeata following 
acute exposure to AgNP (Volker et al., 2013). Regarding the effects of CTAB-AuNR on the development of zebrafish embryos, an all-or-nothing toxic response was observed. While low concentrations of AuNR suspensions do not appear to interfere in zebrafish development, exposure to concentrations of $72 \mu \mathrm{g} / \mathrm{L}$ and up to $104 \mu \mathrm{g} / \mathrm{L}$ produced developmental malformations, including pericardial edema and tail deformities. Moreover, these concentrations also induced a delay in development of head and eyes, elongation of the tail and in the onset of pigmentation, which may have resulted from an impairment of associated cellular processes that occur during the gastrula and segmentation periods. This initial retardation in embryo development might induce repercussions later on as CTABAuNR might produce subsequent cascade of alterations, which may not be detected structurally or functionally until later in the life cycle. Further, zebrafish embryos exposed to 72,87 or $104 \mu \mathrm{g} / \mathrm{L}$ of CTAB-AuNR suspensions displayed a reduction in body size, although only significant for 72 and 104 $\mu \mathrm{g} / \mathrm{L}$ compared with control, which demonstrates that exposure to CTAB-AuNR suspensions influence zebrafish embryonic development. Indeed, a fall in zebrafish body size may have severe implications at the individual fitness level that may exert repercussions at the population level, as it might increase susceptibility to predation, disrupt feeding behavior and reduce reproductive success by increasing time to achieve sexual maturation (Peters, 1986; Uusi. Heikkilä et al., 2012). Therefore, it would be worthwhile to investigate how exposure to CTAB-AuNR suspensions affects zebrafish juvenile and/or adult stages, namely feeding and locomotor activities, social interactions (e.g., predator/prey), and reproductive behavior. Adverse effects attributed to exposure to CTAB-AuNR were also observed in other organisms. Four cladoceran species displayed reduced body length when exposed to the CTABAuNR suspension at concentrations ranging from 1.41 to $18.1 \mu \mathrm{g} / \mathrm{L}$ (Galindo, 2014), whereas whiterot fungi exhibited growth inhibition at concentrations between 15.91 to $33 \mathrm{mg} / \mathrm{L}$ (Galindo et al., 2013). Several studies in Drosophila melanogaster, a commonly used alternative in vivo model to assess MNM biological effects, revealed a reduction of adult life span and fertility after adult or larvae exposure as well as phenotypical deformations of wings and eyes
(Alaraby et al., 2016), indicating that AuNP may adversely influence reproduction and development also in other organisms.

CTAB is the most employed surfactant for synthesis of AuNR as it guides the growth of Au seeds into rod-like shaped NP and efficiently prevents aggregation by adsorbing to their surface. However, CTAB is a highly toxic cationic surfactant, and although several methods may be employed to purify the final AuNR suspensions, some free CTAB might remain in solution after purification. Therefore, to evaluate the contribution of $\mathrm{CTAB}$, both adsorbed to the surface of the AuNR and freely dispersed in solution, to the toxic effects induced by the CTAB-AuNR suspension, zebrafish embryos were incubated with $\mathrm{CTAB}$ solutions at the same concentrations present in the CTAB-AuNR tested suspensions. Pure CTAB produced $100 \%$ embryo mortality within $30 \mathrm{~min}$ of exposure at all concentrations tested. This is in agreement with a previous report by Sandbacka et al. (2000) that observed 50\% lethality in Daphnia magna exposed to $0.16 \mu \mathrm{M} \mathrm{CTAB}$, which is lower concentration than the ones tested in our study (8$17 \mu \mathrm{M})$. On the other hand, Alkilany et al. (2009) found that either CTAB-AuNR dispersions or CTAB-containing supernatant resulting from centrifugation of the CTAB-AuNR dispersions produced similar toxicity in human colorectal adenonocarcinoma HT-29 cells. In addition, CTAB-AuNR and free $\mathrm{CTAB}$ were also noted to produce mortality of similar magnitude in Daphnia magna (Bozich et al., 2014). Hence, CTAB itself may account for the acute toxicity observed in embryos exposed to CTABAuNR. In the present study, pure CTAB treatment resulted in a pronounced lethality zebrafish embryos compared to CTAB-AuNR at the same concentrations. Therefore, it is possible that the concentration of CTAB present in the CTAB-AuNR stock suspension was actually less than the quantity provided by the manufacturer, possibly due to degradation, or AuNR might exert a protective function against free CTAB-mediated toxicity by reducing bioavailability. Nevertheless, to clearly determine the contribution of each component, that is, CTAB and AuNR to the toxicity induced by CTAB-AuNR suspension, it would be necessary to test naked AuNR with the same size and shape as those of the tested AuNR and compare the responses induced in zebrafish embryos. 
Under our experimental conditions, uptake of CTAB-AuNR by zebrafish embryos was similar at 48 and $96 \mathrm{hpf}$, corresponding to less than $1 \%$ of the initial administrated concentration. This low rate of Au internalization might be explained by aggregation/ agglomeration of CTAB-AuNR in ZW or from the negative electrostatic potential of CTAB-AuNR in $\mathrm{ZW}$ that does not favor NP interactions with the negatively charged components of the cellular membrane. The similar internalization rate observed before (48 hpf) and after hatching (96 hpf), particularly for the highest tested concentrations $(60-87 \mu \mathrm{g} /$ L), raises two hypotheses: (1) either CTAB-AuNR surpassed the chorion and were internalized by embryos within the first $48 \mathrm{hpf}$ or (2) Au measured at $48 \mathrm{hpf}$ was due to CTAB-AuNR adsorbed to the chorion and accumulation of the AuNR only occurred after hatching. In fact, AuNP were found to diffuse through the chorionic pore canals and reach the inner cell mass of zebrafish embryos, remaining inside them throughout the entire development (Browning et al., 2009, 2013). However, considering that the lethal effect of CTAB-AuNR suspensions on zebrafish embryos was predominantly established within $24 \mathrm{hpf}$ and internalized levels of CTABAuNR were low ( $1 \%$ initial concentration), the second hypothesis is also plausible as adsorption of CTABAuNR to the chorion may hamper gas exchange (oxygen supply) and osmoregulation, both essential for the zebrafish embryonic development. In agreement with our results, Wang et al. (2016) also found an "all-or-nothing" effect in zebrafish embryos exposed to sublethal doses of CTAB-AuNR, with no visible malformations. However, Wang et al. (2016) reported a higher uptake of Au by zebrafish embryos at $8 \mathrm{hpf}(\sim 20 \%)$ comparing to $80 \mathrm{hpf}(\sim 5 \%)$, which is in concordance with the latter theory. In our study, healthy embryos-with no visible phenotypic defects after CTAB-AuNR exposure-were accumulated Au in their tissues, although to a low \% (less than 1\%). This finding brings into question whether long-term deposition of AuNR in the embryo induces toxicity in subsequent life stages. Asharani et al. (2011) also noted that hatched zebrafish embryos exposed to 25 or $50 \mu \mathrm{g} / \mathrm{ml} \mathrm{Au} \mathrm{nanospheres} \mathrm{accumulated} \mathrm{these} \mathrm{NP}$ approximately between 2 and 3\% with no evident signs of toxicity. The uptake of CTAB-AuNR was also demonstrated to occur in Daphnia magna, a low-trophic-level organism. This raises further concerns of potential transfer and magnification in the food web as previously reported for spherical AuNP which were detected in Daphnia magna fed with the unicellular microorganisms Chlamydomonas reinhardtii and Euglena gracilis exposed to these NP (Lee et al., 2015), and for TiO2 NP transferred from Daphnia magna to zebrafish by dietary exposure (Zhu et al., 2010).

To the best of our knowledge, this was the first time that the genotoxic potential of AuNR was investigated in zebrafish embryos. No marked apparent DNA damage was detected in zebrafish embryonic cells both at 48 and $96 \mathrm{hfp}$ following exposure to CTAB-AuNR. However, accumulation of CTABAuNR in zebrafish tissues might elicit delayed genotoxic events, and thus, further research needs to be conducted. In addition, other mechanisms might be responsible for the toxicity observed in zebrafish embryos exposed to CTAB-AuNR such as oxidative stress. In fact, Wan et al. (2015) reported that CTABAuNR with various aspect ratios were cytotoxic to tumor and non-malignant transformed cells by triggering mitochondrial dysfunction and increasing reactive oxygen species (ROS) production.

In summary, CTAB-AuNR at higher concentrations than levels expected to occur in the aquatic compartment produced significant increase in lethal rates and sublethal effects, which might translate into zebrafish fitness impairment at adult stages highlighting the need to perform risk assessment of these MNM in order to establish environmental safety levels. Further research is needed to unravel the mechanisms of action and the properties responsible for AuNR-mediated toxicity and thus support regulatory decisions that safeguard workers, consumers, and the environment and ultimately, assist development of safer MNM and manufacturing processes.

\section{Funding}

This work was supported by FEDER funds through the program COMPETE-Programa Operacional Factores de Competitividade," and by the Portuguese Foundation for Science and Technology (FCT), within the CESAM's strategic program (UID/AMB/50017/2013), the research project Synchrony (PTDC/AAG-MAA/2140/2012). This research was also partially supported by FCT and the European Regional Development Fund (ERDF), in the framework of the program PT2020 and of ERA-NET SIINN through project NanoToxClass (ERA-SIINN/0001/2013). The materials characterization performed was also developed in the scope 
of the project CICECO-Aveiro Institute of Materials, POCI01-0145-FEDER-007679 (Ref. FCT UID/CTM/50011/2013), financed by national funds through the FCT/MEC and when applicable co-financed by FEDER under the PT2020 Partnership Agreement, and also the project MAGICOAT (PTDC/CTM-BIO/2170/2014). JT thanks FCT for the research grant IF/00347/2013.

\section{References}

Alaraby, M., Annangi, B., Marcos, R., and Hernández, A. 2016. Drosophila melanogaster as a suitable in vivo model to determine potential side effects of nanomaterials: A review. J. Toxicol. Environ. Health B 19: 65-104.

Albanese, A. and Chan, W. C. W. 2011. Effect of gold nanoparticle aggregation on cell uptake and toxicity. ACS Nano 5: 5478-5489.

Alkilany, A. M., Nagaria, P. K., Hexel, C. R., Shaw, T. J., Murphy, C. J., and Wyatt, M. D. 2009. Cellular uptake and cytotoxicity of gold nanorods: Molecular origin of cytotoxicity and surface effects. Small. 5: 701-708.

Alkilany, A. M., Thompson, L. B., Boulos, S. P., Sisco, P. N., and Murphy, C. J. 2012. Gold nanorods: their potential for photothermal therapeutics and drug delivery, tempered by the complexity of their biological interactions. Adv. Drug Deliv. Rev. 64: 190-199.

Asharani, P., Lian Wu, Y., Gong, Z., and Valiyaveettil, S. 2011. Comparison of the toxicity of silver, gold and platinum nanoparticles in developing zebrafish embryos. Nanotoxicology 5: 43-54.

Asharani, P. V., Lian Wu, Y., Gong, Z., and Valiyaveettil, S. 2008. Toxicity of silver nanoparticles in zebrafish models. Nanotechnology 19: 255102.

Baptista, P. V., Doria, G., Quaresma, P., Cavadas, M., Neves, C. S., Gomes, I., Eaton, P., Pereira, E., and Franco, R. 2011. Nanoparticles in molecular diagnostics. Prog. Mol. Biol. Transl. Sci. 104: 427-488.

Botha, T. L., Boodhia, K., and Wepener, V. 2016. Adsorption, uptake and distribution of gold nanoparticles in Daphnia magna following long term exposure. Aquat. Toxicol. 170: 104-111.

Boxall, A., Chaudhry, Q., Sinclair, C., Jones, A., Aitken, R., Jefferson, B., and Watts, C. 2017. Current and future predicted environmental exposure to engineered nanoparticles. York, UK: Central Science Laboratory.

Bozich, J. S., Lohse, S. E., Torelli, M. D., Murphy, C. J., Hamers, R. J., and Klaper, R. D. 2014. Surface chemistry, charge and ligand type impact the toxicity of gold nanoparticles to Daphnia magna. Environ. Sci. Nano. 1: 260-270.

Browning, L. M., Huang, T., and Xu, X.-H. N. 2013. Realtime in vivo imaging of size-dependent transport and toxicity of gold nanoparticles in zebrafish embryos using single nanoparticle plasmonic spectroscopy. Interface Focus 3: 20120098.

Browning, L. M., Lee, K. J., Huang, T., Nallathamby, P. D., Lowman, J. E., and Nancy Xu, X.-H. 2009. Random walk of single gold nanoparticles in zebrafish embryos leading to stochastic toxic effects on embryonic developments. Nanoscale. 1: 138-152.

Chithrani, B. D., Ghazani, A. A., and Chan, W. C. 2006. Determining the size and shape dependence of gold nanoparticle uptake into mammalian cells. Nano Lett 6: 662-668.

Dai, Y.-J., Jia, Y.-F., Chen, N., Bian, W.-P., Li, Q.-K., Ma, Y.B., Chen, Y.-L., and Pei, D.-S. 2014. Zebrafish as a model system to study toxicology. Environ. Toxicol. Chem. 33: $11-17$.

Dominguez, G. A., Lohse, S. E., Torelli, M. D., Murphy, C. J., Hamers, R. J., Orr, G., and Klaper, R. D. 2015. Effects of charge and surface ligand properties of nanoparticles on oxidative stress and gene expression within the gut of Daphnia magna. Aquat. Toxicol. 162: 1-9.

Dooley, K. and Zon, L. I. 2000. Zebrafish: A model system for the study of human disease. Curr. Opin. Genet. Dev. 10: 252-256.

Fang, T., Yu, L. P., Zhang, W. C., and Bao, S. P. 2015. Effects of humic acid and ionic strength on $\mathrm{TiO}_{2}$ nanoparticles sublethal toxicity to zebrafish. Ecotoxicol. 24: 2054-2066.

Galindo, T. P. S. 2014. Integrated risk assessment of nanoparticles in tropical and temperate ecosystems. (PhD Dissertation). Portugal: University of Aveiro.

Galindo, T. P. S., Pereira, R., Freitas, A. C., Santos-Rocha, T. A. P., Rasteiro, M. G., Antunes, F., Rodrigues, D., Soares, A. M. V. M., Gonçalves, F., Duarte, A. C., and Lopes, I. 2013. Toxicity of organic and inorganic nanoparticles to four species of white-rot fungi. Sci. Total Environ. 458460: 290-297.

García-Cambero, J. P., García, M. N., López, G. D., Herranz, A. L., Cuevas, L., Pérez-Pastrana, E., Cuadal, J. S., Castelltort, M. R., and Calvo, A. C. 2013. Converging hazard assessment of gold nanoparticles to aquatic organisms. Chemosphere. 93: 1194-1200.

Gatoo, M. A., Naseem, S., Arfat, M. Y., Dar, A. M., Qasim, K., and Zubair, S. 2014. Physicochemical properties of nanomaterials: Implication in associated toxic manifestations. Biomed. Res. Int. 2014: 498420.

Grzelczak, M., Pérez-Juste, J., Mulvaney, P., and Liz-Marzán, L. M. 2008. Shape control in gold nanoparticle synthesis. Chem. Soc. Rev. 37: 1783-1791.

Gunduz, N., Cevlan, H., Guler, M. O., and Tekinay, A. B. 2017. Intracellular accumulation of gold nanoparticles leads to inhibition of macropinocytosis to reduce the endoplasmic reticulum stress. Sci. Rep. 7: 40493.

Hartmann, N. B., Jensen, K. A., Baun, A., Rasmussen, K., Rauscher, H., Tantra, R., Cupi, D., Gilliland, D., Pianella, F., and Riego Sintes, J. M. 2015. Techniques and protocols for dispersing nanoparticle powders in aqueous media-is there a rationale for harmonization? J. Toxicol. Environ. Health B. 18: 299-326.

Hornos Carneiro, M. F. and Barbosa, F., Jr. 2016. Gold nanoparticles: A critical review of therapeutic applications and toxicological aspects. J. Toxicol. Environ. Health B. 19: 129-148.

Jana, N. R., Gearheart, L., and Murphy, C. J. 2001. Wet chemical synthesis of high aspect ratio cylindrical gold nanorods. J. Phys. Chem. B 105: 4065-4067. 
Janát-Amsbury, M., Ray, A., Peterson, C., and Ghandehari, H. 2011. Geometry and surface characteristics of gold nanoparticles influence their biodistribution and uptake by macrophages. Eur. J. Pharm. Biopharm. 77: 417-423.

Kermanizadeh, A., Gosens, I., MacCalman, L., Johnston, H., Danielsen, P. H., Jacobsen, N. R., Lenz, A.-G., Fernandes, T., Schins, R. P. F., Cassee, F. R., Wallin, H., Kreyling, W., Stoeger, T., Loft, S., Møller, P., Tran, L., and Stone, V. 2016. A multilaboratory toxicological assessment of a panel of 10 engineered nanomaterials to human health-ENPRA project-the highlights, limitations, and current and future challenges. J. Toxicol. Environ. Health B. 19: 1-28.

Kimmel, C. B., Ballard, W. W., Kimmel, S. R., Ullmann, B., and Schilling, T. F. 1995. Stages of embryonic development of the zebrafish. Dev. Dynam. 203: 253-310.

Kosmehl, T., Hallare, A. V., Reifferscheid, G., Manz, W., Braunbeck, T., and Hollert, H. 2006. A novel contact assay for testing genotoxicity of chemicals and whole sediments in zebrafish embryos. Environ. Toxicol. Chem. 25: 2097-2106.

Kumar, A., Zhang, X., and Liang, X.-J. 2013. Gold nanoparticles: Emerging paradigm for targeted drug delivery system. Biotechnol. Adv. 31: 593-606.

Lasagna-Reeves, C., Gonzalez-Romero, D., Barria, M. A., Olmedo, I., Clos, A., Sadagopa Ramanujam, V. W., Urayama, A., Vergada, I., Kogan, M. J., and Soto, C. 2010. Bioaccumulation and toxicity of gold nanoparticles after repeated administration in mice. Biochem. Biophys. Res. Commun. 393: 649-655.

Lee, W.-M., Yoon, S.-J., Shin, Y.-J., and An, Y.-J. 2015. Trophic transfer of gold nanoparticles from Euglena gracilis or Chlamydomonas reinhardtii to Daphnia magna. Environ. Pollut. 201: 10-16.

Li, N., Zhao, P., and Astruc, D. 2014. Anisotropic gold nanoparticles: Synthesis, properties, applications, and toxicity. Angew. Chem. Int. Ed. 53: 1756-1789.

Lima, D., Castro, L. F., Coelho, I., Lacerda, R., Gesto, M., Soares, J., André, A., Capela, R., Torres, T., Carvalho, A. P., and Santos, M. M. 2015. Effects of tributyltin and other retinoid receptor agonists in reproductive-related endpoints in the zebrafish (Danio rerio). J. Toxicol. Environ. Health. 78: 747-760.

Luyts, K., Napierska, D., Nemery, B., and Hoet, P. H. M. 2013. How physico-chemical characteristics of nanoparticles cause their toxicity: Complex and unresolved interrelations. Environ. Sci. Process Impacts 15: 23-38.

Lyche, J. L., Grześ, I. M., Karlsson, C., Nourizadeh-Lillabadi, R., Aleström, P., and Ropstad, E. 2016. Parental exposure to natural mixtures of persistent organic pollutants (POP) induced changes in transcription of apoptosis-related genes in offspring zebrafish embryos. J. Toxicol. Environ. Health. 79: 602-611.

Organisation for Economic Cooperation and Development (OECD). 2013. Test No. 236: Fish Embryo Acute Toxicity (FET) TEST. Paris, France: OECD Publishing.

Pan, J.-F., Buffet, P.-E., Poirier, L., Amiard-Triquet, C., Gilliland, D., Joubert, Y., Pilet, P., Guibbolini, M., De
Faverney, C. R., and Roméo, M. 2012. Size dependent bioaccumulation and ecotoxicity of gold nanoparticles in an endobenthic invertebrate: The tellinid clam Scrobicularia plana. Environ. Pollut. 168: 37-43.

Park, S., Woodhall, J., Ma, G., Veinot, J. G. C., and Boxall, A. B. A. 2015. Do particle size and surface functionality affect uptake and depuration of gold nanoparticles by aquatic invertebrates? Environ. Toxicol. Chem. 34: 850-859.

Peters, R. H. 1986. The ecological implications of body size. Cambridge: Cambridge University Press.

Qian, H., Pretzer, L. A., Velazquez, J. C., Zhao, Z., and Wong, M. S. 2013. Gold nanoparticles for cleaning contaminated water. J. Chem. Technol. Biotechnol. 88: 735-741.

Saha, K., Agasti, S. S., Kim, C., Li, X., and Rotello, V. M. 2012. Gold nanoparticles in chemical and biological sensing. Chem. Rev. 112: 2739-2779.

Sandbacka, M., Christianson, I., and Isomaa, B. 2000. The acute toxicity of surfactants on fish cells, Daphnia magna and fish -A comparative study. Toxicol. In Vitro 14: 61-68.

Singh, N. P., McCoy, M. T., Tice, R. R., and Schneider, E. L. 1988. A simple technique for quantitation of low levels of DNA damage in individual cells. Exp. Cell Res. 175: 184-191.

Tarantola, M., Pietuch, A., Schneider, D., Rother, J., Sunnick, E., Rosman, C., Pierrat, S., Sönnichsen, C., Wegener, J., and Janshoff, A. 2011. Toxicity of gold-nanoparticles: synergistic effects of shape and surface functionalization on micromotility of epithelial cells. Nanotoxicology 5: 254-268.

Tedesco, S., Doyle, H., Blasco, J., Redmond, G., and Sheehan, D. 2010. Exposure of the blue mussel, Mytilus edulis, to gold nanoparticles and the pro-oxidant menadione. Comp. Biochem. Physiol. Part C 151: 167-174.

Teles, M., Fierro-Castro, C., Na-Phatthalung, P., Tvarijonaviciute, A., Trindade, T., Soares, A. M. V. M., Tort, L., and Oliveira, M. 2016. Assessment of gold nanoparticle effects in a marine teleost (Sparus aurata) using molecular and biochemical biomarkers. Aquat. Toxicol. 177: 125-135.

Uusi-Heikkilä, S., Kuparinen, A., Wolter, C., Meinelt, T., and Arlinghaus, R. 2012. Paternal body size affects reproductive success in laboratory-held zebrafish (Danio rerio). Environ. Biol. Fish 93: 461-474.

Volker, C., Boedicker, C., Daubenthaler, J., Oetken, M., and Oehlmann, J. 2013. Comparative toxicity assessment of nanosilver on three Daphnia species in acute, chronic and multi-generation experiments. Plos One. 8: e75026.

Wan, J., Wang, J.-H., Liu, T., Xie, Z., Yu, X.-F., and Li, W. 2015. Surface chemistry but not aspect ratio mediates the biological toxicity of gold nanorods in vitro and in vivo. Sci. Rep. 5: 11398.

Wang, Z., Xie, D., Liu, H., Bao, Z., and Wang, Y. 2016. Toxicity assessment of precise engineered gold nanoparticles with different shapes in zebrafish embryos. Roy. Soc. Chem. Adv. 6: 33009-33013.

Weber, D. N., Hoffmann, R. G., Hoke, E. S., and Tanguay, R. L. 2015. Bisphenol A exposure during early development induces sex-specific changes in adult zebrafish social interactions. J. Toxicol. Environ. Health. 78: 50-66. 
Wong, S. W., Leung, P. T., Djurisic, A. B., and Leung, K. M. 2010. Toxicities of nano zinc oxide to five marine organisms: influences of aggregate size and ion solubility. Anal. Bional. Chem. 396: 609-618.

Wray, A. T. and Klaine, S. J. 2015. Modeling the influence of physicochemical properties on gold nanoparticle uptake and elimination by Daphnia magna. Environ. Toxicol. Chem. 34: 860-872.

Xia, K., Zhang, L., Huang, Y., and Lu, Z. 2015. Preparation of gold nanorods and their applications in photothermal therapy. J. Nanosci. Nanotechnol. 15: 63-73.

Yu, P., Blondeau, J.-P., Andreazza, C., Ntsoenzok, E., Roussel, J., Dutheil, P., Thomann, A.-L., Caillard, A., Mustapha, E., and Meot, J. 2015. Influence of gold nanoparticles (Au NPs) for performance improvement of a-Si: $\mathrm{H}$ photovoltaic cells. Plasmonics 10: 691-701.
Zhao, J. and Castranova, V. 2011. Toxicology of nanomaterials used in nanomedicine. J. Toxicol. Environ. Health B. 14: 593-632.

Zhou, W., Gao, X., Liu, D., and Chen, X. 2015. Gold nanoparticles for in vitro diagnostics. Chem. Rev. 115: 10575-10636.

Zhu, X., Wang, J., Zhang, X., Chang, Y., and Chen, Y. 2010. Trophic transfer of $\mathrm{TiO}_{2}$ nanoparticles from Daphnia to zebrafish in a simplified freshwater food chain. Chemosphere. 79: 928-933.

Zhu, X. S., Tian, S. Y., and Cai, Z. H. 2012. Toxicity assessment of iron oxide nanoparticles in zebrafish (Danio rerio) early life stages. Plos One. 7: e46286.

Zhu, X. S., Wang, J. X., Zhang, X. Z., Chang, Y., and Chen, Y. S. 2009. The impact of $\mathrm{ZnO}$ nanoparticle aggregates on the embryonic development of zebrafish (Danio rerio). Nanotechnology 20: 195103. 